\title{
Dehydrins in maritime pine (Pinus pinaster) and their expression related to drought stress response
}

\author{
Tania Velasco-Conde $\cdot$ Igor Yakovlev • \\ Juan Pedro Majada • Ismael Aranda • Øystein Johnsen
}

Received: 22 March 2011 /Revised: 8 January 2012 / Accepted: 6 February 2012 /Published online: 6 March 2012

(C) Springer-Verlag 2012

\begin{abstract}
Maritime pine (Pinus pinaster) is an important commercial species throughout its Atlantic distribution. With the anticipated increase in desiccation of its habitat as a result of climate change, the selection of genotypes with increased survival and growth capability under these conditions for breeding programs is of great interest for this species. We aimed to study the response to a realistic drought stress under controlled conditions, looked for a method to measure dehydration resistance, and analyzed dehydrin expression in drought-resistant and drought-sensitive clones from different ecotypes. We report here the sequence characteristics and the expression patterns of five dehydrins from $P$. pinaster, along with the physiological characterization of drought stress
\end{abstract}

\section{Communicated by S. González-Martínez}

Electronic supplementary material The online version of this article (doi:10.1007/s11295-012-0476-9) contains supplementary material, which is available to authorized users.

T. Velasco-Conde $(\bowtie) \cdot$ J. P. Majada

Servicio Regional de Investigación y Desarrollo Agroalimentario, SERIDA,

Finca Experimental "La Mata", 1333820 Grado, Asturias, Spain

e-mail: tanveco@yahoo.es

I. Yakovlev

The Norwegian Forest and Landscape Institute,

Høgskoleveien 8,

1432 Ås, Norway

\section{Aranda}

Departamento de Sistemas y Recursos Forestales, CIFOR, Instituto Nacional de Investigación y Tecnología Agraria, Carretera de La Coruña, Km. 7.5,

28040 Madrid, Spain

\section{Ø. Johnsen}

Department of Plant and Environmental Sciences,

Norwegian University of Life Sciences,

1432 Ås, Norway responses in different genotypes (clonally replicated plants), originating from a broad geographical distribution across France and Spain (provenances). In total, we distinguished five different dehydrin genes in silico, grouped into two types $-\mathrm{K}_{2}$ and $\mathrm{SK}_{\mathrm{n}}$. Three of the dehydrin genes had several sequence variants, differing by multiple or single amino acid substitutions. Only two of the dehydrins (PpinDhn3 and PpinDhn4) showed an increase in transcription with increased drought stress which was dependent on provenance and genotype, suggesting their involvement in drought resistance. The other dehydrins showed decreased expression trends with increased severity of the drought stress. The lack of close association between the drought stress and expression patterns of these dehydrin genes suggest that they could have other functions and not be involved in drought resistance. Our results suggest large differences in function between different dehydrin genes.

Keywords Dehydrins - Drought tolerance Pinus pinaster . qRT-PCR . Water potential

\section{Introduction}

Maritime pine (Pinus pinaster Ait.) is one of the major and most widely distributed forest species of the occidental Mediterranean basin and the Atlantic coastal region of southern Europe (Miguel Pérez et al. 2002; González-Martínez et al. 2004, 2005; Wahid et al. 2006), extensively used in plantations and highly relevant for Iberian forestry (Alía et al. 1995; Alía and Martín 2003). Currently, there is considerable interest in selecting genotypes which maintain growth performance under drought conditions (Nguyen-Queyrens and Bouchet-Lannat 2003).

Global warming and the associated likely increase in the incidence of drought in southern regions is one of the most 
severe environmental stresses that affects plant survival and productivity (Rampino et al. 2006). Drought resistance is a physiological concept that includes both "dehydration avoidance" and/or "dehydration tolerance". When plants are exposed to drought, they initially maintain high water status or cellular hydration level (desiccation postponement; see Taiz and Zeiger 2006) and then develop dehydration tolerance, defined as the relative capacity to sustain or conserve plant function in a dehydrated state (Blum 2005).

Some studies have concluded that $P$. pinaster may be among those species that postpone desiccation, because it has adopted several mechanisms to reduce loss of water (e.g., adjustment of water content; osmotic adjustment, with accumulation of osmolites such as proline, glutamate, and sugars; stomatal closure; alterations in root development, etc.), thus enabling growth to be maintained under drought conditions. Because $P$. pinaster has high intraspecies variability and also shows geographic variation in response to drought (Nguyen-Queyrens and Bouchet-Lannat 2003), researchers have found it difficult to develop pertinent criteria for the selection of drought tolerant or sensitive genotypes.

Several physiological parameters have been used to study the response to drought. One of the most informative is the measurement of water potential, which provides information on both soil and plant state (Ritchie and Hinckley 1975). In addition, during water deficit, the expression of a large number of genes is modified, giving rise to strict regulation of the physiological stress responses which is controlled by many factors (Rampino et al. 2006). Among the genes involved in stress responses identified, dehydrins are, so far, those most often considered relevant to dehydration stress. They are desiccation-induced proteins (Artlip and Wisniewski 1997) produced in response to dehydration during environmental stress such as drought (Campbell and Close 1997), low temperatures or freezing (Rinne et al. 1999; Welling et al. 2004; Yakovlev et al. 2008), and increased salinity (Close 1997; Rorat et al. 2006). Dehydrins are also known as the late embryogenesis abundant (LEA) proteins, belonging to the LEA DII family, and they accumulate in plant tissues in response to cellular dehydration resulting from developmental events (Tompa and Kovacs 2010) such as during the late stage of seed maturation, but their exact function remains unclear. In spite of this, different studies suggest that dehydrins may participate in establishing the stress tolerance of plants by taking on a protector function thereby mitigating the damage caused by the stress (Close et al. 1993; Battaglia et al. 2008; Bies-Ethève et al. 2008; Hara 2010; Tompa and Kovacs 2010).

The dehydrins are characterized by the presence of different amino acid motifs, Y-, S-, and K-motifs. They are divided into five subclasses based on their number and order: YnSKn, SKn, Kn, YnKn, and KnS (Close et al.
1993; Campbell and Close 1997). The Y-segment (T/ VDEYGNP) is found near the N-terminal region (there can be between one and three copies), and they might work in the same way as the nucleotide binding site of chaperones (Close 1997). The S-motif, a phosphorylatable serine tract containing five to eight residues, participates in nuclear targeting of the dehydrins (Close 1997). The $\mathrm{K}$ segment is a conserved lysine-rich, 15-amino-acid sequence (EKKGIMDKIKEKLPG) that is found in all dehydrin genes, generally near the C-terminal region (Kosová et al. 2007). There may be one or several copies of this region (Rorat et al. 2006) which act as an interface between hydrophobic membrane phospholipids and the hydrophilic cytosol in plant cells, forming an amphipathic helix (Close 1997; Campbell and Close 1997; Hara et al. 2009). Additionally, there are usually polar amino acids, called $\Phi$-segments, which are interspersed between the conserved segments.

In the last 20 years, different, but structurally related dehydrins have been isolated from crops (Close et al. 1989; Ismail et al. 1999; Zhu et al. 2000; Borovskii et al. 2002; Lee et al. 2005; Bhattarai and Fettig 2005; Hinniger et al. 2006), herbaceous plants (Ouvrard et al. 1996; Volaire 2002; OlaveConcha et al. 2004; Yakubov et al. 2005; Pulla et al. 2008; Bies-Ethève et al. 2008), and woody plants (Arora and Wisniewski 1994; Muthalif and Rowland 1994; Artlip et al. 1997; Rinne et al. 1999; Wisniewski et al. 1999, 2006; Richard et al. 2000; Kontunen-Soppela et al. 2000; Caruso et al. 2002; Welling et al. 2004; Porat et al. 2004; Deng et al. 2006; Yakovlev et al. 2008; Bassett et al. 2009; Hara et al. 2009; Vornam et al. 2011). An accumulation in leaves and stems has been demonstrated, which appears to change during the yearly seasonal cycle.

In this study, we analyzed the response of droughtresistant and drought-sensitive genotypes of $P$. pinaster originating from the latitudinal and altitudinal range of distribution (Fernández et al. 1999; Eveno et al. 2008; Aranda et al. 2010; Sánchez-Gómez et al. 2010). They were exposed to repetitive drought under controlled conditions, and their state was assessed using several physiological methods. We made an in silico search and analysis of dehydrins among available Pinus expressed sequence tags (ESTs) and genomic sequences. Furthermore, we studied the expression of five dehydrin genes (PpinDhn1-5) found in needles in relation to the pine's ability to tolerate long drought periods. The expression was quantified by real-time quantitative RTPCR (qRT-PCR).

Several of the dehydrins analyzed in this study have been described previously, although they may have been given different names (see Table 3 and Electronic supplementary material 1, for more specific information). This work extends the information of the dehydrins of $P$. pinaster and knowledge of their structure and possible functions in relation to drought resistance. 


\section{Material and methods}

\section{Plant material}

Clonal material of maritime pine ( $P$. pinaster Aiton) from three provenances, Oria (Spain), Coca (Spain), and Mimizán (France), were chosen based on differences in climatic characteristics at the sites of seed origin (Mediterranean, Continental, and Atlantics, respectively), to represent the likely range in drought tolerance (Fernández et al. 1999; Eveno et al. 2008; Aranda et al. 2010; Sánchez-Gómez et al. 2010). Within each of the three provenances, two different genotypes, one drought-tolerant and one drought-sensitive, were used. The clones were preselected based on a previous assessment in a greenhouse experiment of survival; 12 seedlings from 223 genotypes were kept in a hydroponic culture and subjected to progressive increases in water stress mediated by the additions of an osmoticum (polyethylene glycol 8000) to the nutrient solution until reaching $-2 \mathrm{MPa}$ after 8 months. Early characterization to drought tolerance was expressed as the number of days to reach $50 \%$ mortality/survival $\left(\mathrm{T}_{50}\right.$ value, unpublished data) (Table 1).

The clones were propagated in 2005 as rooted cuttings from stock being grown in a greenhouse. After several months, they were transplanted to 2-1 containers filled with peat/perlite $(70: 30 \mathrm{v} / \mathrm{v})$ and were placed in a greenhouse in "La Mata" Asturias, Spain (43 $32^{\prime}$ N $7^{\circ} 00^{\prime}$ W, 65 m). At the end of 2008 , the trees were moved into a climatically controlled chamber with a day/night temperature of $25 \pm 2^{\circ} \mathrm{C}$, $60 \pm 10 \%$ relative humidity, and $16 / 8 \mathrm{~h}$ of daylight/night. They were acclimated for 1 month in the new conditions, watered three times a week, and supplemented with mineral elements once a week (1:0.42:1.47, $\mathrm{N} / \mathrm{P}_{2} \mathrm{O}_{5} /$ $\mathrm{K}_{2} \mathrm{O}$ ). The drought treatment was then implemented for 1 month. Three ramets for each genotype, i.e., 18 3-year-old cuttings in total were used.

\section{Drought treatment, harvests, and measurements}

The plants were fully watered (field capacity) prior to the start of the experiment. In the first two weeks of the trial, the plants were left to dry out to the point of $5 \%$ soil water content (water reduction treatment, until $50 \%$ of initial pot weight was reached), followed by a 1-week acclimation treatment under this condition. Subsequently, they were subjected to a 1-week period without watering, showing values near to 0 (drought treatment, until $37 \%$ of initial pot weight was reached) (Aranda et al. 2010). Finally, the plants were re-watered to field capacity for 2 weeks (recovery period).

The water content of the pots was measured by gravimetric measurements every day and monitored with time domain reflectometry (TDR; Topp et al. 1980; Topp and Davis 1985) sensors throughout the experimental period. Water was added in order to maintain the level of stress according to TDR and gravimetric measurements (Fig. 1).

Several needles were collected every week for needle predawn water potential measurements $\left(\Psi_{\text {nwpd }}\right)$, using the Scholander chamber (PMS Instruments, Corvallis, OR, USA) as described by Scholander et al. (1965) and Turner (1988).

Three harvests were made during the experiment: the first, at the beginning of the trial prior to the water reduction treatment, the second, at the end of the 1-week acclimation period following the water reduction treatment, and the third at the end of the drought treatment. For each of these harvests, approximately $1 \mathrm{~g}$ of needles was collected from each tree and immediately frozen in liquid nitrogen for dehydrin analysis. To measure the osmotic potential $\left(\Psi_{\pi}\right)$, three further needles per tree were collected at each harvest and frozen in liquid nitrogen. Sap osmolality was measured with a thermocouple psychrometer (C52 chamber, Wescor, USA) using $10 \mu \mathrm{l}$ sap samples. To obtain the needle relative water content (RWC), two further needles were weighted immediately after each harvest (fresh weight (FW)), then placed in water to obtain their fresh weight at full hydration $\left(\mathrm{FW}_{100}\right)$, and finally dried at $70^{\circ} \mathrm{C}$ for $48 \mathrm{~h}$ to obtain their dry weight (DW). RWC was calculated using the following equation:

$\mathrm{RWC}=(\mathrm{FW}-\mathrm{DW}) /\left(\mathrm{FW}_{100}-\mathrm{DW}\right)$

To compare plants' physiological responses to the treatments, the $\Delta$ of different parameters (RWC, $\Psi_{\pi}$, and $\Psi_{\text {wnpd }}$ ) were calculated as the difference between treatments (Table 2): with $a$ being the difference between second harvest (water reduction treatment) and first harvest (field capacity), and $b$ the difference between third harvest (drought treatment) and second harvest (water reduction treatment). In this way, the rise in accumulated solutes $\left(\Delta \Psi_{\pi}\right)$ was quantified by comparing the difference between the initial and final $\Psi_{\pi}$, between treatments.

$\Delta \Psi_{\pi}^{\mathrm{a}}=\Psi_{\pi 2}-\Psi_{\pi 1}$ and $\Delta \Psi_{\pi}^{b}=\Psi_{\pi 3}-\Psi_{\pi 2}$

Loss of water was calculated as increase/decrease in RWC:

$\Delta \mathrm{RWC}(\%)^{\mathrm{a}}=\mathrm{RWC}_{2}-\mathrm{RWC}_{\mathrm{i}}$ and

$\Delta \mathrm{RWC}(\%)^{\mathrm{b}}=\mathrm{RWC}_{3}-\mathrm{RWC}_{2}$

And the increase in $\Psi_{\text {nwpd }}$ as:

$\Delta \Psi_{\text {nwpd }}{ }^{\mathrm{a}}=\Psi_{\text {nwpd } 2}-\Psi_{\text {nwpdi }}$ and

$\Delta \Psi_{\mathrm{nwpd}}{ }^{\mathrm{b}}=\Psi_{\mathrm{nwpd} 3}-\Psi_{\mathrm{nwpd} 2}$

Gene searching and in silico sequence analysis

An initial search of dehydrin genes was performed with BLAST (tblastn) using Y-segment (T/VDEYGNP), Ksegment (KIKEKLPG), and S-motif amino acid virtual probes, 
comparing the results against those of the National Centre for Biotechnology Information (NCBI) database restrained by Pinus taxa. The obtained sequences were used for a subsequent BLAST (blastn) search against NCBI nucleotide and EST databases, again confined to the Pinus taxa. Collected genomic fragments and ESTs were aligned and combined into contigs for in silico full-length gene construction. Contig clusters were considered as separate dehydrin genes. Multiple sequence alignment was made using WWW resources: Multiple Sequence Alignment (MultAlin) Interface (http://bioinfo. genotoul.fr/multalin/multalin.htm) (Corpet 1988) and TCoffee (http://tcoffee.vital-it.ch/cgi-bin/Tcoffee/tcoffee_cgi/ index.cgi) (Notredame et al. 2000). To obtain the exon-intron structure of the defined genes, the fragments of cDNA and gDNA were aligned using the Spidey mRNA program for genomic alignment at the NCBI (http://www.ncbi.nlm.nih. gov/IEB/Research/Ostell/Spidey/spideywebeg.html).

Translated amino acid sequence alignments and phylogenetic tree construction for the selected dehydrin gene models were conducted using the MEGA software version 4.1 (Tamura et al. 2007) using the neighbor-joining method with default parameters.

\section{RNA isolation}

Total RNA was extracted using Spectrum ${ }^{\mathrm{TM}}$ Plant Total RNA kit (Sigma, St. Louis, MS, USA, \#STRN50) with a minor change from the manufacturer's instructions to improve the extraction: instead of using $500 \mu \mathrm{l}$ of binding solution and $500 \mu \mathrm{l}$ of lysis solution/2ME-mixture, we used 750 and $700 \mu$, respectively (page 5 and protocol A, page 7 of instruction manual). Contaminating DNA was removed from total RNA samples using the DNA-Free ${ }^{\mathrm{TM}}$ kit (Ambion, Austin, TX, USA, \#1906) following the manufacturer's protocol.

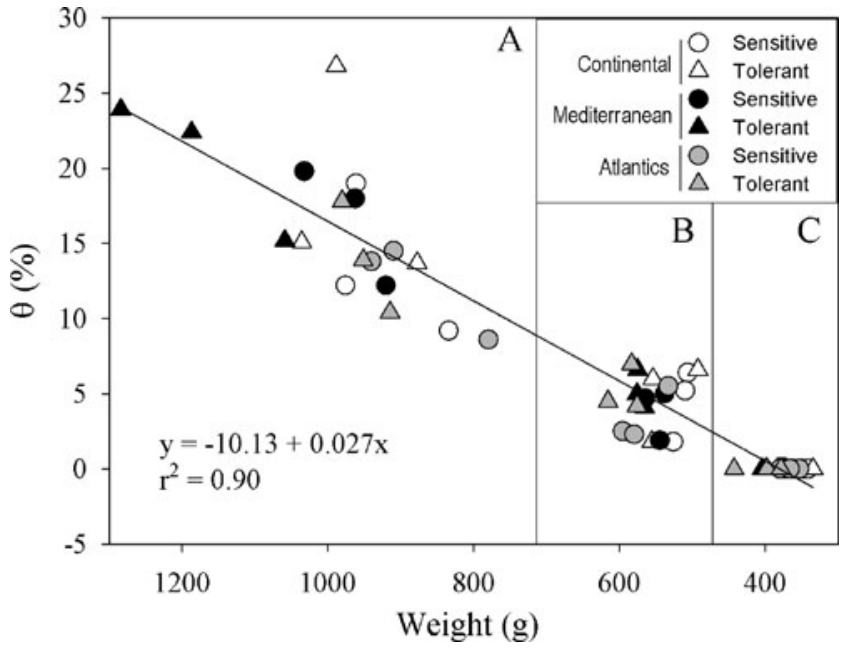

Fig. 1 Correlation between available water, measured with TDR and the weight of pots at three different times during the experiment: a well-watered plants; $\mathbf{b}$ water reduction treatment; $\mathbf{c}$ drought treatment 
Table 2 Increase in osmotic potential $\left(\Psi_{\pi}\right)$, relative water content (RWC), and predawn water potential ( $\left.\Psi_{\text {nwpd }}\right)$ of 3-year-old ramets of $P$. pinaster dependent on water deficit treatments

\begin{tabular}{llllllllrr}
\hline Genotype & \multicolumn{1}{l}{$\Psi_{\pi \mathrm{i}}$} & \multicolumn{1}{c}{$\Delta \Psi_{\pi}^{\mathrm{a}}$} & $\Delta \Psi_{\pi}^{\mathrm{b}}$ & $\mathrm{RWC}_{\mathrm{i}}(\%)$ & $\Delta \mathrm{RWC}(\%)^{\mathrm{a}}$ & $\Delta \mathrm{RWC}(\%)^{\mathrm{b}}$ & $\Psi_{\text {nwpdi }}$ & $\Delta \Psi_{\text {nwpd }}{ }^{\mathrm{a}} \Delta \Psi_{\text {nwpd }} \mathrm{b}^{\mathrm{b}}$ \\
\hline COCA_F3P5 & $-1.987 \mathrm{ab}$ & $-0.385 \mathrm{a}$ & $0.744 \mathrm{~b}$ & $100 \mathrm{a}$ & $-4.8 \mathrm{a}$ & $-0.2 \mathrm{a}$ & $-0.45 \mathrm{~b}$ & $0.00 \mathrm{~b}$ & $-0.97 \mathrm{a}$ \\
COCA_F2P4 & $-1.903 \mathrm{a}$ & $0.117 \mathrm{a}$ & $-0.143 \mathrm{a}$ & $97.8 \mathrm{a}$ & $-2.2 \mathrm{a}$ & $-3.8 \mathrm{a}$ & $-0.62 \mathrm{~b}$ & $0.22 \mathrm{~b}$ & $-1.62 \mathrm{a}$ \\
MIMI_F2P1 & $-1.950 \mathrm{a}$ & $0.121 \mathrm{a}$ & $-0.138 \mathrm{a}$ & $97.8 \mathrm{~b}$ & $-1.1 \mathrm{~b}$ & $-5.2 \mathrm{a}$ & $-0.70 \mathrm{~b}$ & $0.07 \mathrm{~b}$ & $-0.89 \mathrm{a}$ \\
MIMI_F2P2 & $-1.764 \mathrm{a}$ & $0.432 \mathrm{a}$ & $-0.571 \mathrm{a}$ & $99.1 \mathrm{a}$ & $-1.0 \mathrm{a}$ & $-1.3 \mathrm{a}$ & $-0.48 \mathrm{~b}$ & $-0.19 \mathrm{~b}$ & $-0.98 \mathrm{a}$ \\
ORIA_F1P3 & $-1.797 \mathrm{~b}$ & $-0.426 \mathrm{a}$ & $0.612 \mathrm{~b}$ & $97.0 \mathrm{a}$ & $-1.9 \mathrm{a}$ & $-5.2 \mathrm{a}$ & $-0.48 \mathrm{~b}$ & $0.05 \mathrm{~b}$ & $-1.62 \mathrm{a}$ \\
ORIA_F4P4 & $-2.100 \mathrm{a}$ & $0.253 \mathrm{a}$ & $0.015 \mathrm{a}$ & $99.4 \mathrm{~b}$ & $-4.3 \mathrm{ab}$ & $-3.0 \mathrm{a}$ & $-0.50 \mathrm{~b}$ & $-0.07 \mathrm{~b}$ & $-1.03 \mathrm{a}$ \\
\hline
\end{tabular}

Parameters with the same letter are not significantly different at $P=0.05$ (Tukey's test)

i values for control plant

${ }^{a}$ Increase between harvests 1 and 2

${ }^{\mathrm{b}}$ Increase between harvests 2 and 3

RNA was quantified using GeneQuant spectrophotometric OD260 measurements, and quality was assessed by $\mathrm{OD}_{260} / \mathrm{OD}_{280}$ ratios, followed by electrophoresis on $1 \%$ agarose gels stained with ethidium bromide. All RNA was stored at $-80^{\circ} \mathrm{C}$.

\section{cDNA synthesis}

cDNA was synthesized from $1 \mu \mathrm{g}$ of total RNA using the Taqman Reverse Transcription Reagents (Applied Biosystems, Foster City, CA, USA, \#N8080234) according to the manufacturer's procedure. Reverse transcription was carried out in a $50-\mu 1$ reaction volume containing $500 \mu \mathrm{M}$ of dNTPs mixture (2.5 mM each), $2.5 \mu \mathrm{M}$ of oligo d(T) $)_{16}, 1 \times$ TaqMan RT buffer, $5.5 \mathrm{mM}$ of $\mathrm{MgCl}_{2}$ solution, $0.4 \mathrm{U} / \mu \mathrm{l}$ of RNase Inhibitor, and $1.25 \mathrm{U} / \mu \mathrm{l}$ of Multiscribe Reverse Transcriptase. Reactions were incubated at $25^{\circ} \mathrm{C}$ for $10 \mathrm{~min}$, then at $48^{\circ} \mathrm{C}$ for $30 \mathrm{~min}$, and $95^{\circ} \mathrm{C}$ for $5 \mathrm{~min}$ to inactivate the reverse transcriptase in a GeneAmp ${ }^{\circledR}$ PCR System 9700 (Applied Biosystems). After heat-deactivation of the enzyme, ss cDNA obtained was diluted twice and stored at $-80^{\circ} \mathrm{C}$.

\section{Quantitative real-time PCR (qRT-PCR)}

Specific primers for reference genes and dehydrins were designed using Primer 3 software (http://biotools.umassmed. edu/bioapps/primer3_www.cgi) (Rozen and Skaletsky 2000). Primers were designed to have a size of 19-27 base pairs (bp), with $\mathrm{GC}$ content of $44-69 \%$ and $\mathrm{Tm}$ of $67-71^{\circ} \mathrm{C}$. Other aspects were also taken into account such as likelihood of primer selfannealing and formation of dimers. The predicted fragment size ranged from 80 to $100 \mathrm{bp}$ (Electronic supplementary material 1). Oligonucleotides were synthesized by Invitrogen (Paisley, UK) and Eurofins MWG Operon (Ebersberg, Germany).
Real-time PCR reactions were performed in a $25-\mu 1$ volume containing $250 \mathrm{nM}$ of each primer, $2 \mu \mathrm{l}$ of cDNA, and $1 \times$ SYBR Green PCR master mix (Applied Biosystems \#4309155). Real-time PCR was performed on the 7500 Real-Time PCR System (Applied Biosystems) using the parameters for absolute quantification experiment recommended by the manufacturer $(2 \mathrm{~min}$ at $50^{\circ} \mathrm{C}, 10 \mathrm{~min}$ at $95^{\circ} \mathrm{C}$, and 40 cycles of $95^{\circ} \mathrm{C}$ for $15 \mathrm{~s}$ and $60^{\circ} \mathrm{C}$ for $1 \mathrm{~min}$ ). Each PCR reaction was repeated twice, giving three experimental replications. We used the geometric mean of the three reference genes PpinAct1, PpinAct2, and PpinaTub as the internal control. The transcripts of these genes were all more homogeneous (unaffected by the treatments) than other tested genes such as the Ubiquitin gene (PpinUbq) and RNA Polymerase II (PpinRpolII) (Brunner et al. 2004; Yakovlev et al. 2006) (Electronic supplement 2).

The specificity of the amplifications was verified at the end of the PCR run using 7500-system SDS Dissociation Curve Analysis Software, ensuring that only one distinct peak was present. Results were then averaged from different replicates, since the expression patterns were almost equal.

Statistical analysis

Data acquisition and analysis was carried out using the 7500 real-time PCR system SDS software for absolute quantification and then MS Excel software. The relative amounts of transcript were subjected to statistical analysis as described previously by Johnsen et al. (2005a, b). The quantitative data used in the analysis of the transcripts was delta $\mathrm{Ct}$ (threshold cycle) of cDNA obtained from mRNA of three 3-year-old ramets of three different provenances and two different tolerance levels (droughttolerant and drought-sensitive). The analysis corresponds to a randomized complete block design with three replicates, 
using SAS/STAT ${ }^{\circledR}$ Software (US and Canada), following a linear model for the expected value of general response $y_{\mathrm{ijk}} 1$ :

$Y_{\mathrm{ijkl}}=\mu+P_{\mathrm{i}}+C_{\mathrm{j}}+T_{\mathrm{k}}+P C_{\mathrm{ij}}+P T_{\mathrm{ik}}+C T_{\mathrm{jk}}+P C T_{\mathrm{ijk}}+e_{\mathrm{ijk}}$

where $\mu$ is the general mean; $P, C$, and $T$ represent the additive fixed main effects of provenance $(P)$, category $(C)$ (sensitive or tolerant), and treatment $(T)$ (well-watered, $5 \%$ available water, and withholding water), respectively. PC is the interaction between provenance and category; PT is the interaction between provenance and treatment; $\mathrm{CT}$ is the interaction between category and treatment, and PCT is the interaction between all possible effects: provenance, category, and treatment. $e_{\mathrm{ijk}}$ is the residual value of the individual values of $i, j, k, l$.

Analysis of variance (one-way ANOVA), using an SPSS 15.0 Inc. ${ }^{\circledR}$ Win $^{\mathrm{TM}}$ statistics package (SPSS, Richmond, CA), was applied to the data in order to discriminate between genotypes and drought treatments. Comparisons of means were made using post hoc comparisons with the Tukey's test $(P<0.05)$. No significant interactions between main effects were obtained.

Relationships between variables and different graphics were made using SigmaPlot ${ }^{\circledR} 10.0$ procedures (2006 Systat Software, Inc.).

\section{Results}

Plant material and drought treatment

Throughout the experimental period, soil and leaf water status were monitored by measuring the gravimetric soil water content, the volumetric content of water $(\theta, \%$, measured with TDR technology), and the needle predawn water potential $\left(\Psi_{\text {nwpd }}\right)$. A negative linear relationship $\left(r^{2}=0.90\right)$ was obtained between gravimetric values (pot weight) and $\theta$ over the time exposed to drought, indicating available water for plants throughout the treatment period (Fig. 1). Part A presents the water status in the well-watered plants (maintained at field capacity) prior to drought. Continental and Mediterranean genotypes maintained relatively higher $\theta$ values than Atlantic genotypes. During the water reduction treatment (part B), water availability was drastically reduced to $28.29 \%$, and the mean weight of pots decreased to $56.78 \%$. Both genotypes of the Continental and Atlantic provenances consumed a similar quantity of water $(\approx 55 \%$ and $\approx 63 \%$, respectively). In the Mediterranean provenance, the sensitive genotype consumed a higher amount of water compared with the tolerant genotype (56.48\% and 48.62, respectively). For the Atlantic provenance, the average use of water was lower than in the other provenances (between $8 \%$ and $11 \%$ ). In part $\mathrm{C}$, all plants exposed to severe drought, i.e., no available water, no differences between genotypes were found.
Predawn leaf (needle) water potential $\left(\Psi_{\text {nwpd }}\right)$ is an indicator of water availability in the soil near the root system, reflecting plant water status (Nguyen-Queyrens et al. 2002). $\Psi_{\text {nwpd }}$ (megapascals) values measured during the experiment are shown in Fig. 2. Part A shows the condition of plants before the water reduction treatment, where quite similar values in $\Psi_{\text {nwpd }}$ (approximately $-0.5 \mathrm{MPa}$ ) were obtained in each provenance and genotype. Part $\mathrm{B}$ shows the values from the successive measurements taken during the water reduction treatment during which soil water content was reduced and maintained at approximately $5 \%$. During this period, $\Psi_{\text {nwpd }}$ initially decreased in both genotypes of the Continental and Atlantic provenances as well as the Mediterranean sensitive genotype and then returned to levels nearly as high as in the well-watered period. The $\Psi_{\text {nwpd }}$ of the tolerant Mediterranean genotype, however, remained the same as in part A. Following the water reduction period, the drought regime was established (part C) and $\Psi_{\text {nwpd }}$ values further decrease. This was most pronounced in the Mediterranean and the Continental provenances, where quite clear opposite trends between tolerant and sensitive genotypes were observed. For the Atlantic provenance, we did not find any consistent difference between the tolerant and sensitive genotypes, suggesting an interaction between provenance and clone category. During the re-watering period (part D), no general pattern of recovery from drought stress to higher water potentials was found. However, $66 \%$ of the plants of each genotype from the Continental provenance, and 33\% of the sensitive genotype from the Atlantic provenance died. There was zero mortality among the plants from the Mediterranean provenance and the tolerant Atlantic genotype. In the sensitive genotypes, only that from the Mediterranean provenance recovered to $-1.0 \mathrm{MPa}$, when re-watered.

\section{Plant water relations}

Table 2 shows the osmotic potential $\left(\Psi_{\pi}\right)$, the RWC, and predawn water potential $\left(\Psi_{\text {nwpd }}\right)$. The delta $(\Delta)$ parameters were estimated as the differences between periods ( $a$ and $b$ ) during the drought treatment.

For the Continental provenance, only the sensitive genotype showed a passive osmotic adjustment with a reduction in RWC $\left(4.8 \%\right.$ for $\left.\Delta^{\mathrm{a}}\right)$, and significant differences between treatments were observed (Table 2) at $P<0.05$ (one-way ANOVA, post hoc Tukey's test). In period a, this was the genotype which showed the largest differences, though it was closely followed by the sensitive genotype of the Mediterranean provenance, although this latter did not show any changes in RWC. The tolerant genotype of Atlantic provenance showed a non-significant active osmotic adjustment during period $\mathrm{b}$ $\left(\Delta \Psi_{\pi}-0.571 \mathrm{MPa}\right)$ without significant differences in RWC. The remaining genotypes did not show any significantly different osmotic adjustment. 


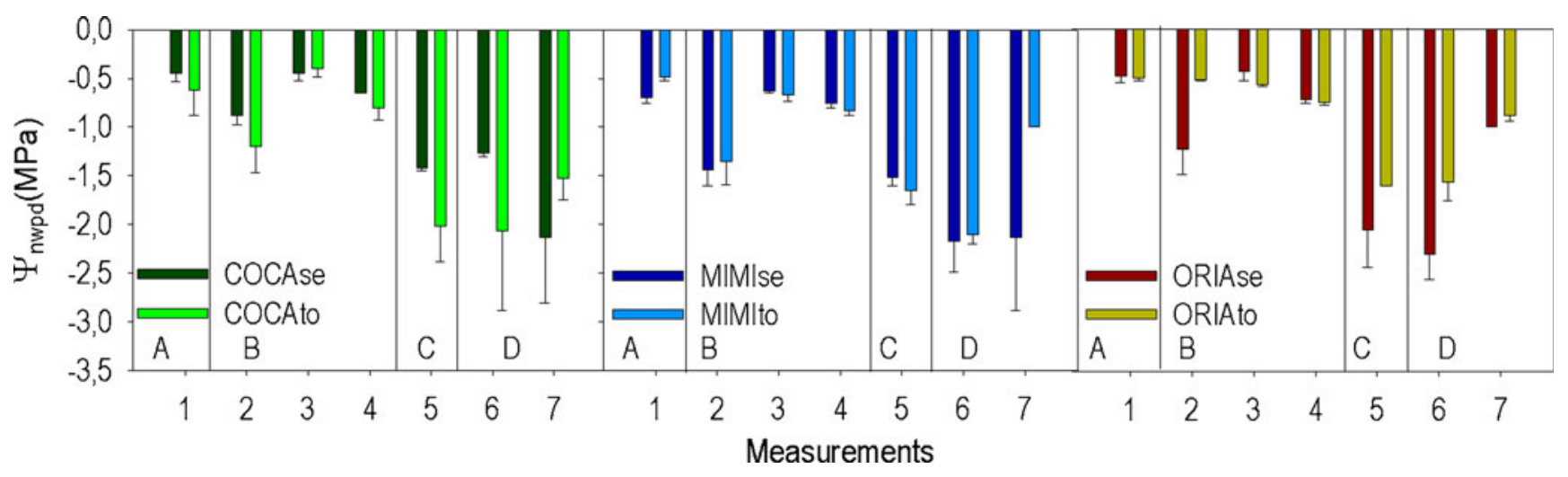

Fig. 2 Needle predawn potential ( $\Psi_{\text {nwpd, }}$ megapascals) measured during the experiment: a well-watered plants (point 1$)$; b water reduction treatment (points 2, 3, and 4); $\mathbf{c}$ drought treatment (point 5); $\mathbf{d}$ recovery period, after re-watering of plants (points 6 and 7)

With regards $\Delta \Psi_{\text {nwpd, }}$, all genotypes showed significant differences between treatments $(P<0.05)$ : the highest being obtained in the drought treatment for all genotypes. The lowest values for $\Psi_{\text {nwpd }}$ were observed in the sensitive genotype of Mediterranean provenance $(-2.05 \mathrm{MPa})$ and in the tolerant genotype of Continental provenance $(-2.02 \mathrm{MPa})$, at the end of the experiment.

\section{Sequences and structure of the dehydrins}

The search of the GenBank EST database, confined to Pinus genus, revealed a large set of ESTs and genomic sequences containing dehydrin-specific S- and K- amino acid motifs. However, we did not find any sequences containing a dehydrin-specific Y-motif. All ESTs were aligned and combined in contigs based on nucleotide sequences. The contigs obtained allowed, in most cases, the construction of fulllength cDNA with complete open reading frames (ORFs). They were also aligned with dehydrin genomic sequences allowing us to obtain the intron-exon structures of putative dehydrin $(D h n)$ gene models. In total, we defined and characterized five different $D h n$ genes in $P$. pinaster, three of which (PpinDhn1, PpinDhn2, and PpinDhn5) had several (at least two) sequence variants, differing by single or several amino acid substitutions (Fig. 3). Based on the presence of the dehydrin-specific amino acid S- and K-motifs (Close 1996; Campbell and Close 1997), we grouped the five Dhn models into two types, as shown in Table 3.

The first type of $P$. pinaster dehydrin was the most abundant and included six ESTs containing S- and K-motifs, which we defined as a SKn-type dehydrins. The first of these, PpinDhn1.1, encoded a putative protein of 238 amino acids (aa), had one described intron between position 248 and $355 \mathrm{bp}$, and contained four K- segments (K(I/S)KEK(L/I) $\mathrm{PG}$ ) and an S-motif of eight-serine residues upstream of the first K-motif. PpinDhn1.2 encoded a putative protein of 238 aa with four different K-motifs (K(I/N)KEK(I/L)(P/H)(G/A)) and an S-motif of six serine residues and two aa substitutions. Its genomic sequence contains one intron between 333 and $486 \mathrm{bp}$. The protein sequences of PpinDhn2.1 and PpinDhn2.2 differed only in three aa. Each had an ORF of 582 bp encoding a protein of 193 aa; their structure was formed by two Kmotifs, K(I/T)KEK(I/L)PG followed by an S-motif with eight-serine residues. PpinDhn 3 had one ORF of $516 \mathrm{bp}$, encoding a putative protein of 171 aa, two K-motifs (KIK(E/ D)KLPG), and nine-serine residues. PpinDhn4 had a full length of $1,755 \mathrm{bp}$ with an ORF of $981 \mathrm{bp}$, contained one intron of 572-905 bp in the S-motif, and had a structure of five K-motifs $(\mathrm{K}(\mathrm{I} / \mathrm{T} / \mathrm{F}) \mathrm{K}(\mathrm{E} / \mathrm{K}) \mathrm{K}(\mathrm{L} / \mathrm{V}) \mathrm{P}(\mathrm{G} / \mathrm{A} / \mathrm{V}))$ and seven-serine residues.

The second dehydrin type was categorized as a $K n$-type. It had no S-motif, and the amino acid sequences had only two Kmotifs. PpinDhn5.1 with an ORF of 309 bp encoded a protein of 102 aa and contained two K-motifs (KIKEKLPG), and PpDhn5.2 had one ORF of $270 \mathrm{bp}$, encoded a protein of 89 aa, and also contained two K-motifs (KIK(E/Q)KLPG).

Phylogenic relationships of $P$. pinaster dehydrins

The full-length dehydrin coding regions of various other woody plants, among which were other Pinus species, Picea abies, Cupressus sempervirens, Ginkgo biloba, Rhododendron catawbiense, Betula pubescens, Tamarix hispida, Pyrus pyrifolia, Malus domestica, Populus species, Prunus species, and Citrus species, were aligned using the ClustalW program (Larkin et al. 2007) and their phylogenetic tree (constructed using MEGA software version 4.1, Tamura et al. 2007).

This tree (Fig. 4) was then used to compare the translated aa sequences of the $P$. pinaster with the other woody plant dehydrins. Fourteen groups combining dehydrins from different species and structure types $\left(\mathrm{Y}_{\mathrm{n}} \mathrm{SK}_{\mathrm{n}}, \mathrm{Y}_{\mathrm{n}} \mathrm{K}_{\mathrm{n}}, \mathrm{K}_{\mathrm{n}} \mathrm{S}, \mathrm{S}, \mathrm{SK}_{\mathrm{n}}\right.$, $\mathrm{K}_{\mathrm{n}}$ ) were found. The Genbank accession numbers of the analyzed sequences are given in the Electronic supplementary material 3. 
Fig. 3 Alignment of the deduced amino acid sequences of $P$. pinaster dehydrins: a type $1\left(\mathrm{SK}_{\mathrm{n}}\right)$ and $\mathbf{b}$ type $2\left(\mathrm{~K}_{\mathrm{n}}\right)$. The boxes indicate the S-motif and the K-motifs
A

$\mathrm{SK}_{\mathrm{n}}-\mathrm{typ}_{\mathrm{yp}}$

PpinDhn1 . 1

PpinDhn1.2

PpinDhn2.1

PpinDhn2.2

PpinDhn3

PpinDhn4

Ppindhn1 . 1

PpinDhn1.2

PpinDhn2.1

PpinDhn2.2

PpinDhn3

PpinDhn4

PpinDhn1 . 1

PpinDhn1.2

PpinDhn2.1

Ppindhn2. 2

PpinDhn3

PpinDhn4

PpinDhn1.1

PpinDhn1.2

PpinDhn2.1

PpinDhn2. 2

PpinDhn3

PpinDhn4

PpinDhn1.1 PpinDhn1.2 Ppindhn2.1 PpinDhn2.2 PpinDhn3

PpinDhn4

PpinDhn1.1 PpinDhn1.2 PpinDhn2.1 PpinDhn2.2 PpinDhn3 Ppindhn4

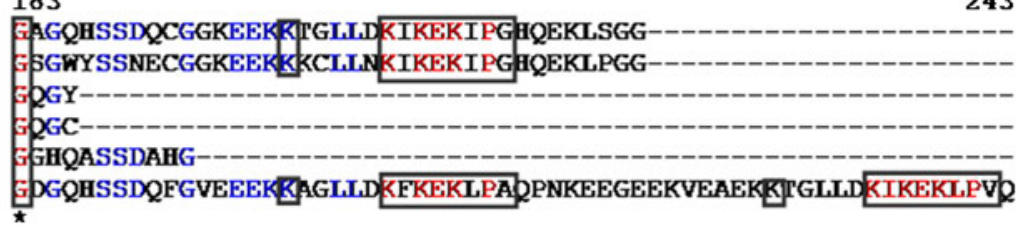

244

304

---GTHSSDECGVKEEK R TIGLD KIREKIPG HQEKPPGDGKHS--------SDEHGGEEE ---GTHSSDQCRGKEEKK K RILDOKIKEKIPA IQEKLPGDGKQS---------SDEHGGEEE -------------EEGK K TGLVG KIKEKIPG HQEKLPGDGKQYPGEHEKQYYRQHGSEEE -------------EEGK W TGLVG KIKEKIPG IQEKLPGDGKQYPGEHEKQYSRQHGSEEE

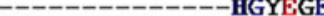
SNQGEREEKEEKVEVEK WGILD KIKEKLPG ISNKKEGEGKE-----------EEEAEVQ

$305 \quad 337$

KR LGVLG KIKEKLPG IKNQKNDAEEEEKKHHH KKLGVLG KIKEKLPG IKNQKNDAEEEEKKHHH KK TGMID KIKEKL.PG HHN-KNDGE-------L KK TGMIDKIKEKLPG BHN-KNDGE-------Q - KGLVDKIKDKLPG HHD-K-------------E KE ISLIDKIKEKLPG MHN-KKEGEEEEKKQNY

$\star::: \star \star \star \star: \star \star \star \star \star::$ :

B

K-Type

PpinDhn5.1 PpinDhn5.2

1

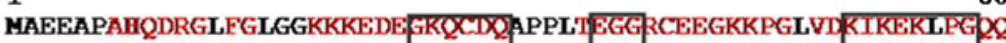
------AHQDRGMFG---KKKEDEEKQCTQ --DEGGRCEEGKKPGMVIKIKEKIPG $Q$ 61 103

PpinDhn5.1 EKL.1 PpinDhn5.2 QKL.PGDGKQCCGQPGGEEEKKPGAVDKIKQKLPGQQNKTGCD

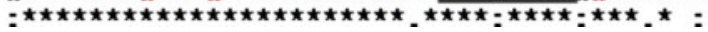

The $P$. pinaster $d h n$ genes were arranged in two different groups within two dhn gene classes. PpinDhn1.1 and
PpinDhn1.2 ( $\mathrm{SK}_{4}$ type) were present in group 1, very close to Pinus ponderosa, Pinus sylvestris, and Pinus concorta 


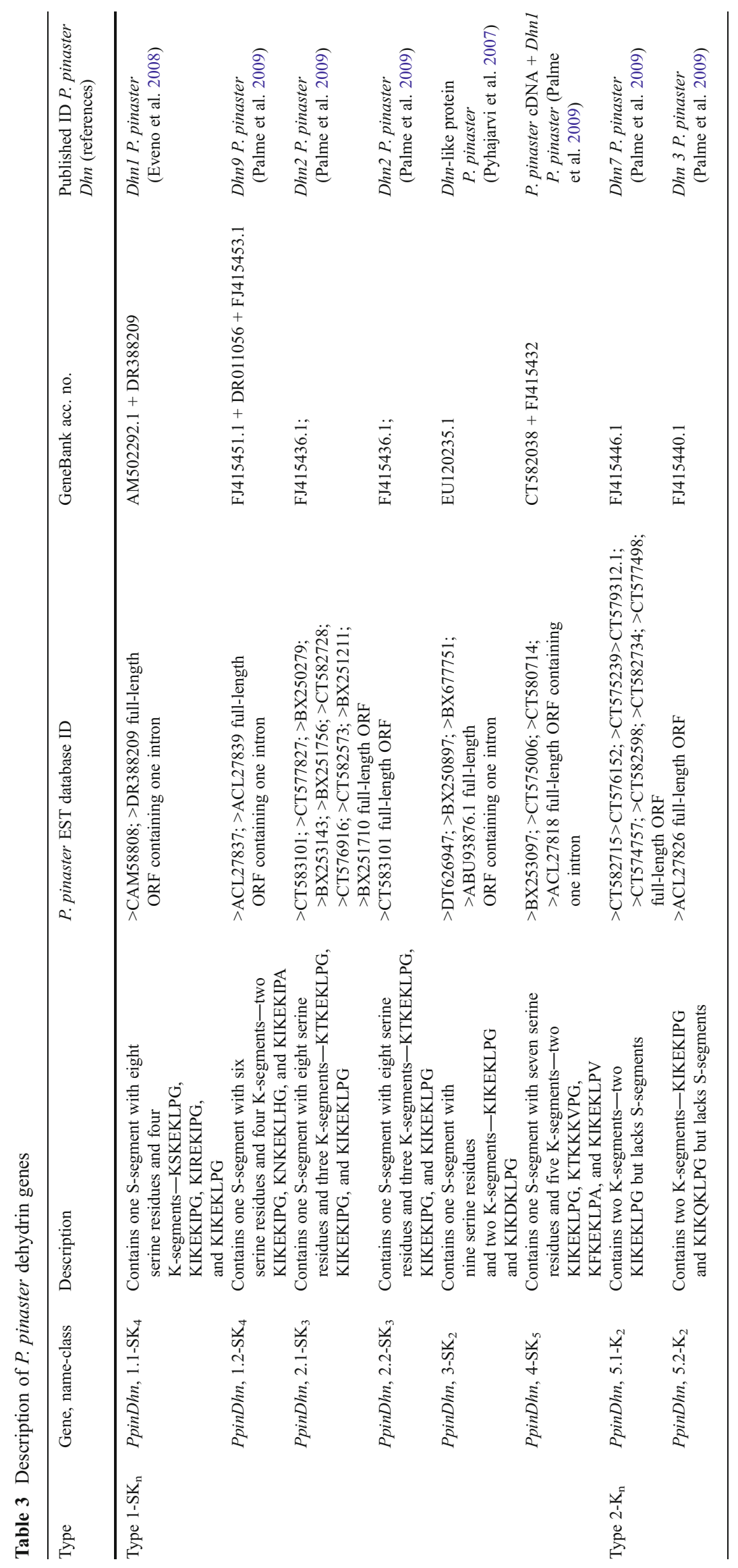


Fig. 4 Phylogenetic tree showing sequence relations between $P$. pinaster dehydrins and selected woody plant dehydrins. Species codes: Ppin: $P$. pinaster; Bp: B. pubescens; Cits: Citrus sinensis; CuS: C. sempervirens; Prp: Prunus pérsica; Th: Tamarix hispida; Pop: Populus nigra, Populus maximowiczii, Populus alba, Populus tremula var glandulosa, Populus tremula var Davidiana, Populus canadienses, Populus $x$ canadienses, Populus trichocarpa; Rc: R. catawbiense; Md: M. x domestica; Prd: Prunus dulcis; Pyp: P. pyrifolia; Gb: G. biloba; Pa: P. abies; Cit: Citrus unshiu; Pt: Pinus taeda; Ps: P. sylvestris; Ppo: P. ponderosa; Pc: P. concorta. For detailed references, see Electronic supplementary material 3. P. pinaster dehydrins highlighted with red boxes. Cluster numbers consist of indication of dehydrin types included into distinct cluster

$\left(\mathrm{SK}_{4}\right)$. PpinDhn $4\left(\mathrm{SK}_{5}\right.$ type) was present in the same group, although more associated with P. sylvestris (PsDhn1.2). PpinDhn3 was placed in group 1 together with dehydrin 2.1 of Pinus tadea (PtDhn2.1), and PpinDhn2.1 and 2.2 were found in the same group, very close to dehydrins belonging to $P$. abies, C. sempervirens, and P. sylvestris. Finally, group 7 was formed by sequences with $\mathrm{K}_{2}$ motifs, which included PpinDhn5.1 and 5.2 from P. pinaster (two proteins that differ in seven gaps and eight aa) together with dehydrins of $P$. sylvestris and $C$. sempervirens.

The remaining groups included dehydrins from different Magnoliphyta orders (Rosales, Caryophyllales, Sapindales, Fagales, Malpighiales, Ericales) together with some Cupressus sempervires dehydrins, with different dehydrin motifs ( $\mathrm{S}$, $\mathrm{SK}_{2}, \mathrm{~K}_{2}, \mathrm{~K}_{3}, \mathrm{~K}_{6}, \mathrm{Y}_{3} \mathrm{SK}, \mathrm{Y}_{2} \mathrm{SK}_{3}, \mathrm{Y}_{2} \mathrm{~K}_{9}, \mathrm{YK}_{3}$ ). Magnoliophyta orders were present in three groups: group 3 with $\mathrm{K}_{2} \mathrm{~S}$-motif, group 5 with a dehydrin structure that included the Y-motif, and group 10 with SK and $\mathrm{SK}_{2}$ motifs. Group 4 included the G. biloba dehydrin with an S-motif structure.

Different dehydrin structures of the $\mathrm{K}_{\mathrm{n}}$ type, belonging to P. abies, C. sempervirens, and Pinus and Populus species, were placed into groups 6,7 , and 8 .

\section{Quantitative real-time PCR (qRT-PCR)}

The expression of dehydrin genes was measured using quantitative real-time PCR of RNA samples isolated from three ramets per genotype of the three $P$. pinaster provenances. The initial sample copy numbers were calculated from the difference between the mean $C t$ and specific $C t$ s for each genotype and treatment (Fig. 5). The statistical model applied to test differences in the expression of dehydrins showed significant differences for all dehydrins $(P<0.05)$. Significant differences in transcription were observed between treatments at $P<0.001$ or $P<0.05$, in the dehydrins studied. Significant differences between provenances were obtained only for PpinDhn1, PpinDhn2, and PpinDhn3 $(P<0.05)$.

PpinDhn1, PpinDhn2, and PpinDhn5 showed similar trends, which indicated decreasing transcript levels as water deficit became more severe. The highest transcript levels were found at the beginning of the experimental period. We found no differences in PpinDhn5 transcript levels between

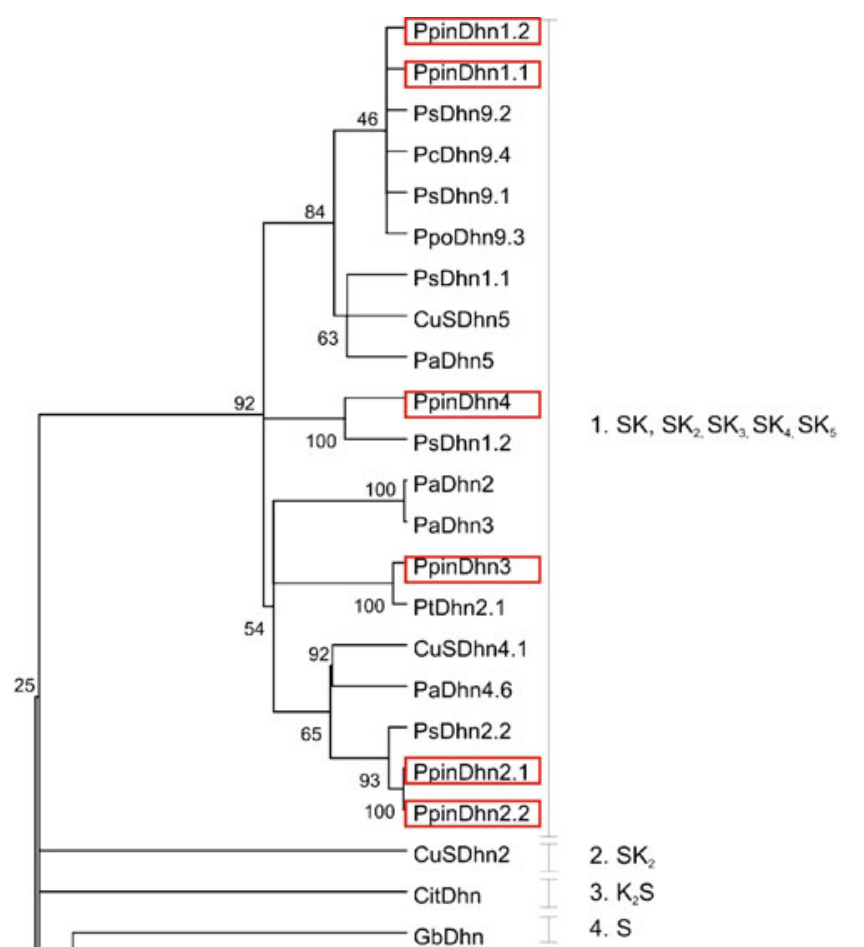

4. S

5. $\mathrm{YK}_{3}, \mathrm{Y}_{2} \mathrm{~K}_{9} \mathrm{Y}_{3} \mathrm{SK}, \mathrm{Y}_{2} \mathrm{SK}_{1}$

6. $\mathrm{K}_{2} \mathrm{~K}_{3}, \mathrm{~K}_{6}$

7. $\mathrm{K}_{2}$

8. $\mathrm{K}_{2}$

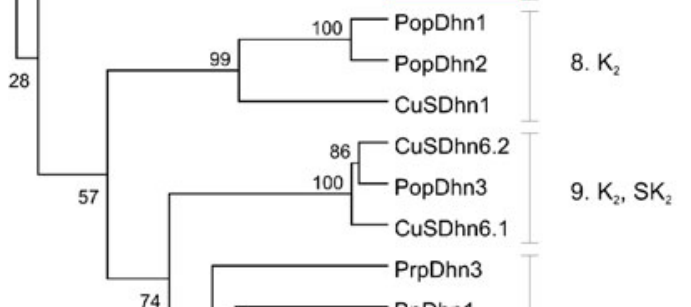

10. SK, SK 

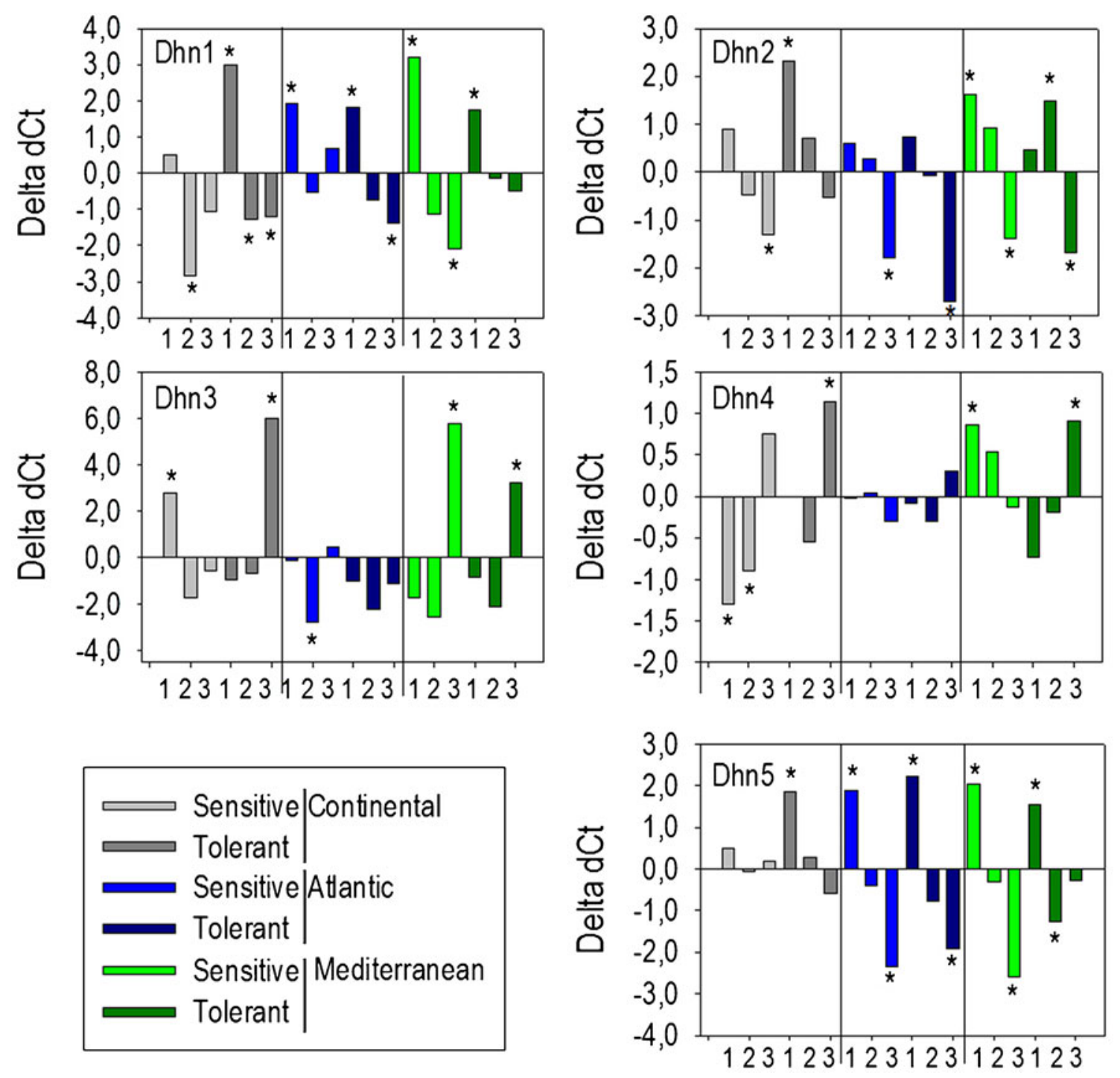

Fig. 5 Expression profiles of dehydrins in drought-sensitive and drought-resistant genotypes of three provenances of maritime pine $(P$. pinaster Aiton): Oria (Spain-Mediterranean), Coca (Spain-Continental), and Mimizán (France-Atlantic). Transcript levels are presented as the difference between geometric mean of three preselected reference

later dropped significantly under severe drought conditions (third sampling point).

Expression patterns of PpinDhn3 and PpinDhn4 differed significantly between different provenances and between drought-sensitive and drought-tolerant genotypes. PpinDhn3 transcript levels increased significantly with increasing drought stress for Mediterranean provenance, more so for the sensitive than the tolerant genotype. The same overall effect was seen in the Continental tolerant genotype where a more than 128-fold rise in transcript levels was found, showing significant differences $(P<0.0001)$ between the beginning and end of the drought stress. However, for the Continental sensitive genotype, onset of drought stress was accompanied by a drastic decrease in dehydrin transcripts, followed by a genes (PpinAct 1 and 2 and PpinTub) and the chosen transcripts relative to the mean value for the genes targets (Delta $\mathrm{dCt}$ ). Asterisks depict significant differences in the interaction among provenance, categories, and treatment $(P<0.05)$. 1: well-watered plants, 2: water reduction treatment and 3: drought treatment

slight recovery when the drought conditions became very severe at the end of the drought treatment. The Atlantic provenance scarcely changed PpinDhn3 expression in relation to the treatments.

PpinDhn4 showed a stable increase in its transcript levels in all tolerant genotypes and also in Continental sensitive genotype. However, the influence of drought stress on Atlantic and Mediterranean sensitive genotypes resulted in a slight though non-significant response in transcript levels. In general, there was a more than three- to fourfold difference between tolerant and sensitive genotype of Continental and Mediterranean provenances and a less than twofold difference was obtained for Atlantic genotypes. 
Accumulation of dehydrin transcripts in relation to the physiological response

Figure 6 shows the relationship between transcription of the dehydrins and predawn water potential $\left(\Psi_{\text {nwpd }}\right)$. For PpinDhn3 and PpinDhn4, an increase in the accumulation of transcript was found when $\Psi_{\text {nwpd }}$ decreased. For the other dehydrins, a decrease in $\Psi_{\text {nwpd }}$ was associated with a decrease in accumulation of transcript, and the overall pattern was similar for resistant and sensitive genotypes. The treatment response pattern for PpinDhn3 and PpinDhn4, however, differed depending on provenance and clone type within provenance. This was particularly clear for PpinDhn3, where we found a strong upregulation under severe drought stress for the sensitive clone of Mediterranean provenance, but this was not so for the sensitive genotypes from the two other provenances (sub-figure A for PpinDhn3). The Atlantic tolerant genotype showed no changes in transcription with increasing drought stress (sub-figure B for PpinDhn3), while the transcription level for two other provenances clearly increased with rising drought stress intensity. An increase in PpinDhn4 transcript levels during severe drought stress was found for the sensitive genotypes of the Continental provenance (sub-figure A for PpinDhn4) but not for the sensitive genotypes from the two other provenances. This increase in transcription of PpinDhn4 during severe drought stress was consistent among all the resistant clones but more pronounced in those from the
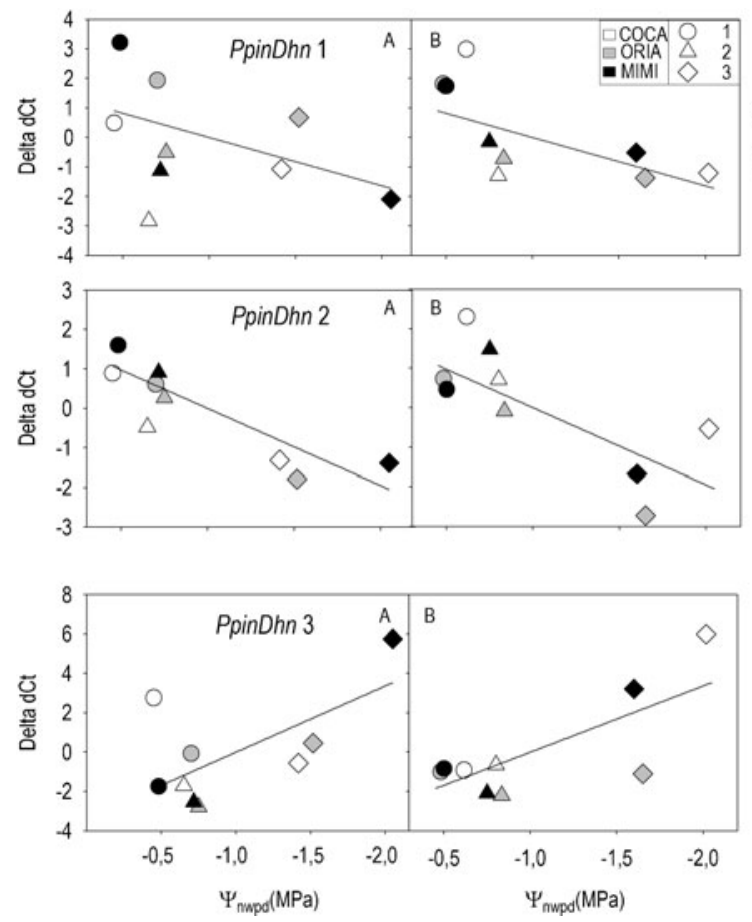

Fig. 6 Relationship between needle predawn water potential ( $\Psi_{\text {nwpd}}$, megapascals) and accumulation of PpinDhn transcripts (cycle difference), expressed as mean values for the genotypes in the different treatments: 1
Continental and Mediterranean provenances (sub-figure B for PpinDhn4).

For the rest of the dehydrins (PpinDhn1, PpinDhn2, and PpinDhn5), the downregulation of transcription during increased drought stress severity was consistent within provenances and within provenance clone types though some minor deviations from this general trend were observed for PpinDhn 1 and PpinDhn5.

\section{Discussion}

The main aim of this experiment was to analyze the gene expression response to a drought period in $P$. pinaster by exposing the plants to a realistic level of drought, i.e., of comparable strength to that which may naturally occur under field conditions. Both drought-resistant and drought-sensitive genotypes from across the species' latitudinal range of distribution (three provenances) (Fernández et al. 1999, 2000; Eveno et al. 2008; Aranda et al. 2010; Sánchez-Gómez et al. 2010) were included in the study and were selected according to the results of a previous experiment (unpublished data). Under drought stress conditions, plants produce an array of proteins as part of a global stress response, which leads to the protection of cell metabolism. From the various hydrophilic proteins produced (Caruso et al. 2002; Wisniewski et al. 2006; Khurana et al. 2008), dehydrins were chosen for analysis here.
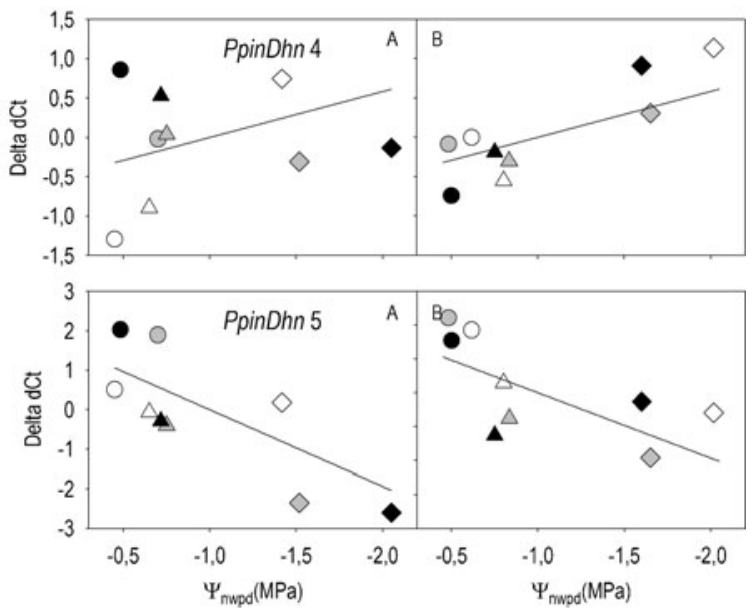

well-watered plants; 2 water reduction treatment; 3 drought treatment. Plot $A$ and plot $B$ correspond with sensitive and tolerant plants, respectively. Significant differences were obtained at $P<0.05$ 
We report here the sequence characteristics and the patterns of expression of five dehydrins from maritime pine, as well as a physiological characterization of samples from droughtexposed plants and their controls. Dehydrin genes were identified based on the pine EST collection at the NCBI. We found relatively high intragenic diversity with several nucleotide (and amino acid) substitutions among the analyzed ESTs, which allowed us to distinguish between several variants of the same gene. We suspect these to be alleles, but further work needs to be carried out to verify. In total, we identified eight dehydrin gene models, combined in five genes. After analyzing the amino acid sequences, we distinguished two different types of dehydrin: $\mathrm{SK}_{\mathrm{n}}$ and $\mathrm{K}_{\mathrm{n}}$. Most dehydrins found in this study (PpinDhn1-PpinDhn4) belong to the $\mathrm{SK}_{\mathrm{n}}$ type and have one S- segment of six to eight serine residues and 2$5 \mathrm{~K}$-segments. Only one of the dehydrins found (PpinDhn5) was of the K-type and had two K-segments. All the dehydrins in this study were shown to have a similar structure, i.e., they lack a Y-segment, as do the dehydrins from other conifers like P. abies (Yakovlev et al. 2008), P. sylvestris, P. concorta, P. ponderosa, or C. sempervires (Fig. 4, Electronic supplementary material 3). Y-segments have in fact only been found in fruit tree dehydrins, such as $M$. domestica, P. pyrifolia, and Prunus sp. (Artlip et al. 1997; Wisniewski et al. 2006) which all contain one Y- segment, and B. pubescens (Welling et al. 2004) which has three Y-segments.

Cluster and phylogenic tree analysis indicated that available dehydrin genes in the woody plants analyzed can be divided into three large groups (Fig. 4). The first includes cluster 1, formed by the order Pinales with an $\mathrm{SK}_{\mathrm{n}}$ structure. The second by deciduous trees belonging to the order Magnoliophyta (clusters 5 and 10) and possessing various different dehydrin structures $\left(\mathrm{SK}_{\mathrm{n}}, \mathrm{K}_{\mathrm{n}} \mathrm{S}, \mathrm{K}_{\mathrm{n}}, \mathrm{Y}_{\mathrm{n}} \mathrm{K}\right.$, and $\mathrm{Y}_{\mathrm{n}} \mathrm{SK}_{\mathrm{n}}$ types). The third group is represented mainly by different conifers from the Pinus, Picea, Populus, and Cupressus taxa and is composed of $\mathrm{K}_{\mathrm{n}}$ dehydrin.

$P$. pinaster dehydrins, although dispersed across two clusters, tended to be very close to other Pinus and C. sempervirens dehydrins but not so closely associated with $P$. abies dehydrins.

Currently, various parameters are commonly used to define the dehydration resistance of a plant. Of these, we decided to apply water deficit to $P$. pinaster ramets for a month, monitoring the soil water content with TDR technology and measuring the gravimetric soil water content (Fig. 1). Throughout the experiment, different levels of water consumption between plants of the same genotype (ramets of a clone) were observed, possibly because of the significant differences in size among ramets of the same clone (Electronic supplementary material 4). However, as water reduction reached the point of $5 \%$ available water in pots, water consumption of different ramets became more similar, showing sensitive genotypes to generally consume more water than the resistant clones, except for the
Continental provenance, where similar consumption levels were seen irrespective of water availability.

Throughout the experiment, $\Psi_{\text {nwpd }}$ values decreased and finally reached values of almost $-2.5 \mathrm{MPa}$. Drought tolerance can clearly be influenced by the origin of the plants (Fernández et al. 1999). During the recovery period, we recorded $66 \%$ and $33 \%$ mortality for Continental and sensitive Atlantic plants, respectively. However, none of the plants of Mediterranean provenance (from Oria in southern Spain) died, thus demonstrating considerably more drought tolerance. This has been demonstrated previously in other studies, e.g., Fernández et al. (2000), which showed that Oria tended to be more efficient in water use than other provenances and Fernández et al. (1999), where it was suggested that plants originating from the region might save more water. The tolerant Continental genotype exhibited lower values of $\Psi_{\text {nwpd }}$ than the sensitive genotype. Although whole plant leaf area, heights, or diameters were not measured, ramets of this genotype were observed to be larger than sensitive ramets. Larger plants are likely to have a higher transpiring leaf area and therefore consume more water. Thus, when these plants are subjected to water limitation in a restricted root volume, the ramets show rapidly decreasing values of water potential (Nguyen-Queyrens et al. 2002). The sensitive genotype of the Mediterranean provenance showed lower $\Psi_{\text {nwpd }}$ values than the tolerant genotype. In this case, ramets of both genotypes were similar in sizes, but in spite of this, the sensitive genotype had a greater transpiring leaf area, and this feature could explain the lower values observed (Electronic supplementary material 4).

qRT-PCR analysis indicated that three dehydrin genes (PpinDhn1, PpinDhn2, and PpinDhn5) were most highly expressed in the well-watered plants. Their transcript levels decreased with increasing drought intensity. Therefore, their regulatory role in drought resistance in maritime pines is quite doubtful, although they could be involved in response to other types of stresses, such as low temperatures or osmotic, salt, or other biotic stresses. The results obtained in this study suggest that, within the dehydrin group of genes, large difference in function may exist.

Though the exact functions of dehydrins in plants are still not clear, they have been shown to be involved in a wide range of adaptive processes (Hara 2010). In trees, levels of dehydrins have been associated with cold hardiness/dormancy and content/state of water in the tissue (Rowland and Arora 1997; Erez et al. 1998; Kalberer et al. 2006). It seems that accumulation of dehydrins is a common feature of cold acclimation and onset of dormancy, and levels of dehydrin transcripts stay very high during the winter (Wisniewski et al. 1996; Yakovlev et al. 2008). Many studies report a positive correlation between the accumulation of dehydrin transcripts or proteins and tolerance to freezing, drought, or salinity (Karlson et al. 2003; Kosová et al. 2007; Mehta et al. 2009; Rampino et al. 2006; Rorat et al. 2006; Tommasini et al. 2008; Wisniewski et al. 
2008; Hara 2010). Joosen et al. (2006) have demonstrated a positive correlation between cold acclimation and upregulation of $\mathrm{K}_{2}$ type dehydrins. However, the same authors point out that the expression of different classes of dehydrins (such as $\mathrm{SK}_{4}$ ) was unrelated to physiological parameters. In our study, $\mathrm{K}_{2}$-type dehydrins, together with $\mathrm{SK}_{3}$ and $\mathrm{SK}_{4}$, showed downregulated expression under water stress and were inversely correlated to drought tolerance, whereas the dehydrins type $\mathrm{SK}_{2}$ and $\mathrm{SK}_{5}$ were upregulated. These results suggest that there is no clear correlation between expression and dehydrin types in conifer species.

The data from in vitro dehydrin studies indicate that dehydrin proteins are involved in a variety of functions during plant growth and in response to dehydration stress, such as the binding of macro- or small molecules, the prevention of protein denaturation, or by performing as antioxidant molecules (Rorat et al. 2006; Hara 2010; Tompa and Kovacs 2010).

Expression patterns for the two genes PpinDhn3 and $P p i n D h n 4$ showed a rather close relationship with the intensity of the drought stress, but revealed different patterns in response to it, depending on provenance and genotype. In the water reduction treatment stage, there was a decrease in transcript levels of PpinDhn3 for all provenances, but this was more marked for the sensitive genotypes than the resistant. Furthermore, the drought treatment phase resulted in an increase in PpinDhn3 transcript levels compared with the level of wellwatered plants in the Atlantic provenance, as well as to levels above those of the well-watered plants for the Continental tolerant and both Mediterranean genotypes.

In summary, we found clear opposite trends in PpinDhn4 expression between sensitive and tolerant genotypes of Mediterranean provenance. Increasing drought conditions were accompanied by an increase in transcript levels in the drought-tolerant genotype but a decrease in the sensitive genotype. In the Continental provenance, we found a trend of increasing PpinDhn4 expression for both the sensitive and tolerant genotypes as drought intensity increased, but the initial PpinDhn4 expression level in well-watered sensitive plants was nearly twice as low as for the tolerant genotype. For Atlantic provenance, no pattern in gene expression was noted. As we did not find any clear relationship between $P$. pinaster PpinDhn3 and PpinDhn4 transcript levels and drought intensity which was common to all genotypes, we tentatively suggest that different provenances use different strategies for survival under drought condition. For example, in the case of the Mediterranean provenance, the difference in PpinDhn3 expression between genotypes could be related to the decrease in $\Psi_{\text {nwpd }}$ at the end of the stress period, possibly explained by water loss and osmotic adjustment (Table 2). There was high expression of PpinDhn3 in the sensitive genotype of this provenance which showed a low $\Psi_{\text {nwpd }}$ and early osmotic adjustment, whereas the tolerant genotype showed a high $\Psi_{\text {nwpd }}$, with no osmotic adjustment and low water loss. This suggests that dehydrins may be regulated osmotically. On the other hand, the tolerant genotype of Continental provenance showed a higher PpinDhn4 expression than the sensitive one: the sensitive genotype showing osmotic adjustment in the first phase of the drought treatment caused by loss of water, while the tolerant genotype expressed osmotic adjustment and decreasing $\Psi_{\text {nwpd }}$ in the final phase. Thus, we may conclude that the early response of the sensitive genotype led to the accumulation of fewer transcripts than in the tolerant genotype, which had a later response to the drought. These results suggest a clear relationship between dehydrin expression, in our case, PpinDhn 3 and PpinDhn4, and drought stress (Fig. 6) using parameters such as water loss or $\Psi_{\text {nwpd }}$, as described by other authors, e.g., Cellier et al. (1998) and Volaire (2003).

Variation in gene expression was found between genotypes and provenances for the dehydrin genes studied (Figs. 5 and 6) and has also been observed in other species (Tschaplinski et al. 1998; Vaseva et al. 2010; Wilkins et al. 2009). Caruso et al. (2002) demonstrated a constitutive expression of PeuDhn 1 transcripts in leaves of Populus euramericana, which increased during drought conditions, but with transcript levels reaching their highest level following 3 days of re-watering rather than in the maximum drought condition. In other studies, it has been necessary to apply severe drought conditions to see large differences in transcript expression (e.g., Cellier et al. 2000).

Our results may also be attributable to other causes: Richard et al. (2000) observed differences in expression between needles, buds, stems, and roots of spruce, and it is also important to note that night/day fluctuations have been found to be significant in Helianthus annuus L (Cellier et al. 2000), with higher transcript levels in the early morning under mild drought and at midday under severe drought. Moreover, in studies of cocksfoot (Dactylis glomerata) (Volaire et al. 2005), dehydrin expression differed between cultivars and seasons. It is also known that dehydrins might show different expression patterns when the stress period is increased, and between seasons and cultivars, as well as between drought-tolerant and droughtsensitive genotypes (Volaire 2002; Cellier et al. 1998).

The complexity of the situation in relation to barley (Hordeum spontaneum) has been described by Suprunova et al. (2004), where the authors hypothesized that higher drought stress resistance could be attributed to the combination of different factors such as the high expression level of dehydrin genes, the presence of more efficient transcription factors, and/ or more efficient signal transduction and early cellular perception of the stress. And Vaseva et al. (2010) observed that some wheat cultivars, defined as resistant to water deficit by means abscisic acid results, were found to be drought-sensitive when dehydrin expression profiles were used. This complexity of the drought-tolerance trait consequently implies that it cannot be genetically analyzed as a monogenetic character. It is obvious that in vitro evidence combined with dehydrins expression 
profiles suggests that their function indeed correlates with the stress-survival of the plants.

Further investigations focusing on other physiological parameters as well as the analysis of expression of dehydrins and other water-stress-related genes are needed to provide further insight into the molecular aspects of drought tolerance in plants and also to clarify the roles of single members of the dehydrin gene family in the general pattern of stress response.

Acknowledgments This work was financially supported in part by the project "Heterogeneidad ambiental y adaptabilidad en respuesta a la sequía en colecciones clonales de Pinus pinaster", Ref. RTA200700084-00-00. T. Velasco was granted an INIA scholarship, Ministerio de Educación y Ciencia of Spain. The authors would like to thank Antonio Fernández, Angelo K. Dantas (Servicio Regional de Investigación y Desarrollo Agroalimentario (SERIDA), Spain), and Inger Heldal (Skogoglandskap, Norway) for their valuable contributions and to Ronnie Lendrum who revised the English.

\section{References}

Alía R, Martín S (2003) EUFORGEN Technical guidelines for genetic conservation and use for maritime pine (Pinus pinaster). International Plant Genetic Resources Institute, Rome, Italy. 6 pp. http:// www.bioversityinternational.org/fileadmin/bioversity/publications/ pdfs/857.pdf

Alía R, Gil L, Pardos JA (1995) Performance of 43 Pinus pinaster provenances on 5 locations in Central Spain. Silvae Genetic $44: 75-81$

Aranda I, Alia R, Ortega U, Dantas AK, Majada J (2010) Intra-specific variability in biomass partitioning and carbon isotopic discrimination under moderate drought stress in seedlings from four Pinus pinaster populations. Tree Gen Genom 6:169-178

Arora R, Wisniewski ME (1994) Cold acclimation in genetically related (sibling) deciduous and evergreen peach (Prunus persica [L.] Batsch) II. A 60-kilodalton bark protein in cold-acclimated tissues of peach $1 \mathrm{~s}$ heat stable and related to the dehydrin family of proteins. Plant Physiol 105:95-101

Artlip T, Wisniewski M (1997) Tissue-specific expression of a dehydrin gene in one-year-old 'Rio Oso Gem' peach trees. J Am Soc Hortic Sci 122:784-787

Artlip TS, Callahan AM, Bassett CL, Wisniewski ME (1997) Seasonal expression of a dehydrin gene in sibling deciduous and evergreen genotypes of peach (Prunus persica [L.] Batsch). Plant Mol Biol 33:61-70

Bassett C, Wisniewski M, Artlip T, Richart G, Norelli J, Farrell R (2009) Comparative expression and transcript initiation of three peach dehydrin genes. Planta 230:107-118

Battaglia M, Olvera-Carrillo Y, Garciarrubio A, Campos F, Covarrubias AA (2008) The enigmatic LEA proteins and other hydrophilins. Plant Physiol 148:6-24

Bhattarai T, Fettig S (2005) Isolation and characterization of a dehydrin gene from Cicer pinnatifidum, a drought-resistant wild relative of chickpea. Physiol Plant 123:452-458

Bies-Ethève N, Gaubier-Comella P, Debures A, Lasserre E, Jobet E, Raynal M, Cooke R, Delseny M (2008) Inventory, evolution and expression profiling diversity of the LEA (late embryogenesis abundant) protein gene family in Arabidopsis thaliana. Plant Mol Biol 67:107-124
Blum A (2005) Drought resistance, water-use efficiency, and yield potential - are they compatible, dissonant, or mutually exclusive? Aust J Agric Res 56:1159-1168

Borovskii GB, Stupnikova IV, Antipina AI, Vladimirova SV, Voinikov VK (2002) Accumulation of dehydrin-like proteins in the mitochondria of cereals in response to cold, freezing, drought and $\mathrm{ABA}$ treatment. BMC Plant Biol 2:1-17

Brunner AM, Yakovlev IA, Strauss SH (2004) Validating internal controls for quantitative plant gene expression studies. BMC Plant Biol 4(14):1-7

Campbell SA, Close TJ (1997) Dehydrins: genes, proteins, and associations with phenotypic traits. New Phytol 137:61-74

Caruso A, Morabito D, Delmotte F, Kahlem G, Carpin S (2002) Dehydrin induction during drought and osmotic stress in Populus. Plant Physiol Biochem 40:1033-1042

Cellier F, Coneéjéro G, Breitler JC, Casse F (1998) Molecular and physiological responses to water deficit in drought-tolerant and drought-sensitive lines of sunflower1: accumulation of dehydrin transcripts correlates with tolerance. Plant Physiol 116:319-328

Cellier F, Conéjéro G, Casse F (2000) Dehydrins transcript fluctuations during a day/night cycle in drought-stressed sunflower. J Exp Bot 51:299-304

Close TJ (1996) Dehydrins: emergence of a biochemical role of a family of plant dehydration proteins. Physiol Plant 97:795-803

Close TJ (1997) Dehydrins: a commonalty in the response of plants to dehydration and low temperature. Physiol Plant 100:291-296

Close TJ, Kortt AA, Chandler PM (1989) A cDNA-based comparison of dehydration-induced proteins (dehydrins) in barley and corn. Plant Mol Biol 13:95-108

Close TJ, Fenton RD, Moonan F (1993) A view of plant dehydrins using antibodies specific to the carboxy terminal peptide. Plant Mol Biol 23:279-286

Corpet F (1988) Multiple sequence alignment with hierarchical clustering. Nucl Acids Res 16:10881-10890

Deng Z, Wang Y, Jiang K, Liu X, Wu W, Gao S, Lin J, Sun X, Tang K (2006) Molecular cloning and characterization of a novel dehydrin gene from Ginkgo biloba. Biosci Rep 26:203-215

Erez A, Faust M, Line MJ (1998) Changes in water status in peach buds on induction, development and release from dormancy. Sci Hort 73:111-123

Eveno E, Collada C, Guevara MA, Léger V, Soto A, Díaz L, Léger P, González-Martínez SC, Cervera MT, Plomion C, Garnier-Geré PG (2008) Contrasting patterns of selection at Pinus pinaster Ait. drought stress candidate genes as revealed by genetic differentiation analyses. Mol Biol Evol 25:417-437

Fernández M, Gil L, Pardos JA (1999) Response of Pinus pinaster Ait. provenances at early age to water supply. I. Water relation parameters. Ann For Sci 56:179-187

Fernández M, Gil L, Pardos JA (2000) Effects of water supply on gas exchange in Pinus pinaster Ait. provenances during their first growing season. Ann For Sci 57:9-16

González-Martínez SC, Mariette S, Ribeiro MM, Burban C, Raffin A, Chambel MR, Ribeiro CAM, Aguiar A, Plomion C, Alía R, Gil L, Vendramin GG, Kremer A (2004) Genetic resources in maritime pine (Pinus pinaster Aiton): molecular and quantitative measures of genetic variation and differentiation among maternal lineages. For Ecol Manag 197:103-115

González-Martínez SC, Gil L, Alía R (2005) Genetic diversity estimates of Pinus pinaster in the Iberian Peninsula: a comparison of allozymes and quantitative traits. Investig Agrar: Sist Recur For 14(1):1-10

Grivet D, Sebastiani F, Alía R, Bataillon T, Torre S, Zabal-Aguirre M, Vendramin GG, González-Martínez SC (2011) Molecular footprints of local adaptation in two Mediterranean conifers. Mol Biol Evol 28(1):101-116

Hara M (2010) The multifunctionality of dehydrins: an overview. Plant Sign Behav 5:503-508 
Hara M, Shinoda Y, Tanaka Y, Kuboi T (2009) DNA binding of citrus dehydrin promoted by zinc ion. Plant Cell Envir 32:532-541

Hinniger C, Caillet V, Michoux F, Ben Amor M, Tanksley S, Lin C, McCarthy J (2006) Isolation and characterization of cDNA encoding three dehydrins expressed during Coffea canephora (Robusta) grain development. Ann Bot 97:755-765

Ismail AM, Hall AE, Close TJ (1999) Purification and partial characterization of a dehydrin involved in chilling tolerance during seedling emergence of cowpea1. Plant Physiol 120:237244

Johnsen Ø, Fossdal CG, Nagy NE, Mølmann J, Dæhlen OG, Skrøppa T (2005a) Climatic adaptation in Picea abies progenies is affected by the temperature during zygotic embryogenesis and seed maturation. Plant Cell Environ 28:1090-1102

Johnsen Ø, Dæhlen OG, Østreng G, Skrøppa T (2005b) Daylength and temperature during seed production interactively affect adaptive performance of Picea abies progenies. New Phytol 168:589-596

Joosen RV, Lammers M, Balk PA, Brønnum P, Konings MC, Perks M, Stattin E, van Wordragen MF, van der Geest AL (2006) Correlating gene expression to physiological parameters and environmental conditions during cold acclimation of Pinus sylvestris, identification of molecular markers using cDNA microarrays. Tree Physiol 26:1297-313

Kalberer SR, Wisniewski M, Arora R (2006) Deacclimation and reacclimation of cold-hardy plants: current understanding and emerging concepts. Plant Sci 171:3-16

Karlson DT, Zeng Y, Stirm VE, Joly RJ, Ashworth EN (2003) Photoperiodic regulation of a $24-\mathrm{kd}$ dehydrin-like protein in red-osier dogwood (Cornus sericea 1.) in relation to freeze-tolerance. Plant Cell Physiol 44:25-34

Khurana P, Vishnudasan D, Chhibbar AK (2008) Genetic approaches towards overcoming water deficit in plants-special emphasis on LEAs. Physiol Mol Biol Plant 14(4):277-298

Kontunen-Soppela S, Taulavuori K, Taulavuori E, Lähdesmäki $\mathrm{P}$, Laine K (2000) Soluble proteins and dehydrins in nitrogenfertilized Scots pine seedlings during deacclimation and the onset of growth. Physiol Plant 109:404-409

Kosová K, Vítámvás P, Prášil IT (2007) The role of dehydrins in plant response to cold. Biol Plant 51(4):601-617

Larkin MA, Blackshields G, Brown NP, Chenna R, McGettigan PA, McWilliam H, Valentin F, Wallace IM, Wilm A, Lopez R, Thompson JD, Gibson TJ, Higgins DG (2007) ClustalW and ClustalX version 2. Bioinformatics 23(21):2947-2948

Lee SC, Lee MY, Kim SJ, Jun SH, An G, Kim SR (2005) Characterization of an abiotic stress-inducible dehydrin gene, OsDhn1, in rice (Oryza sativa L.). Mol Cells 19(2):212-218

Mehta PA, Rebala KC, Venkataraman G, Parida A (2009) A diurnally regulated dehydrin from Avicennia marina that shows nucleocytoplasmic localization and is phosphorylated by casein kinase II in vitro. Plant Physiol Biochem 47:701-709

Miguel Pérez I, González Martínez SC, Alía Miranda R, Gil Sánchez L (2002) Growth phenology and mating system of maritime pine (Pinus pinaster Aiton) in Central Spain. Investig Agrar: Sist Recur For 11(1):193-204

Muthalif MM, Rowland LJ (1994) Identification of dehydrin-like proteins responsive to chilling in floral buds of blueberry (Vaccinium, section Cyanococcus). Plant Physiol 104:1439-1447

Nguyen-Queryens A, Bouchet-Lannat F (2003) Osmotic adjustment in three-year-old seedlings of five provenances of maritime pine (Pinus pinaster) in response to drought. Tree Physiol 23:397-404

Nguyen-Queyrens A, Costa P, Loustau D, Plomion C (2002) Osmotic adjustment in Pinus pinaster cuttings in response to a soil drying cycle. Ann For Sci 59:795-799

Notredame C, Higgins DG, Heringa J (2000) T-coffee: a novel method for fast and accurate multiple sequence alignment. J Mol Biol 302:205-217
Olave-Concha N, Ruiz-Lara S, Muñoz X, Bravo LA, Corcuera LJ (2004) Accumulation of dehydrin transcripts and proteins in response to abiotic stresses in Deschampsia antarctica. Antarct Sci 16(2):175-184

Ouvrard O, Cellier F, Ferrare K, Tousch D, Lamaze T, Dupuis JM, Casse-Delbard F (1996) Identification and expression of water stress and abscisic acid-regulated genes in drought-tolerance sunflower genotype. Plant Mol Biol 31:819-829

Palmé AE, Pyhäjärvi T, Wachowiak W, Savolainen O (2009) Selection on nuclear genes in a Pinus phylogeny. Mol Biol Evol 26(4):893905

Porat R, Pasentsis K, Rozentzvieg D, Gerasopoulos D, Falara V, Samach A, Luriea S, Kanellisc AK (2004) Isolation of a dehydrin cDNA from orange and grapefruit citrus fruit that is specifically induced by the combination of heat followed by chilling temperatures. Physiol Plant 120:256-264

Pulla RK, Kim YJ, Kim MK, Senthil KS, In JG, Yang DC (2008) Isolation of a novel dehydrin gene from Codonopsis lanceolata and analysis of its response to abiotic stresses. BMB Rep 41 (4):338-343

Pyhäjärvi T, García-Gil MR, Knürr T, Mikkonen M, Wachowiak W, Savolainen O (2007) Demographic history has influenced nucleotide diversity in European Pinus sylvestris populations. Genetics 177:1713-1724

Rampino P, Pataleo S, Gerardi C, Mita G, Perrotta C (2006) Drought stress response in wheat: physiological and molecular analysis of resistant and sensitive genotypes. Plant Cell Environ 29:21432152

Richard S, Morency MJ, Drevet C, Jouanin L, Séguin A (2000) Isolation and characterization of a dehydrin gene from white spruce induced upon wounding, drought and cold stresses. Plant Mol Biol 43:1-10

Rinne PLH, Kaikuranta PLM, van der Plas LHW, van der Schoot C (1999) Dehydrins in cold-acclimated apices of birch (Betula pubescens Ehrh.): production, localization and potential role in rescuing enzyme function during dehydration. Planta 209:377388

Ritchie G, Hinckley TM (1975) The pressure chamber as an instrument for ecological research. In: MacFayden A (ed) Advanced in ecological research. Academic Press London, New York, pp 165-201, 9

Rorat T, Szabala BM, Grygorowicz WJ, Wojtowicz B, Yin Z, Rey P (2006) Expression of $\mathrm{SK}_{3}$-type dehydrin in transporting organs is associated with cold acclimation in Solanum species. Planta 224:205-221

Rowland LJ, Arora R (1997) Proteins related to endodormancy (rest) in woody perennials. Plant Sci 126:119-144

Rozen S, Skaletsky HJ (2000) Primer3 on the WWW for general users and for biologist programmers. In: Krawetz S, Misener S (eds) Bioinformatics methods and protocols: methods in molecular biology. Humana Press, Totowa, pp 365-386

Sánchez-Gómez D, Majada J, Alía R, Feito I, y Aranda I (2010) Intraspecific variation in growth and allocation patterns in seedlings of Pinus pinaster. Ait submitted to contrasting watering regimes: can water availability explain regional variation? Annals For Sci 67. DOI: $10.1051 /$ forest $/ 2010007$

Scholander PF, Hammel HT, Bradstreet ED, Hemmingsen EA (1965) Sap pressure in vascular plants. Sci 148:339-346

Suprunova T, Krugman T, Fahima T, Chen G, Shams I, Korol A, Nevo E (2004) Differential expression of dehydrin genes in wild barley, Hordeum spontaneum, associated with resistance to water deficit. Plant Cell Environ 27:1297-1308

Taiz L, Zeiger E (2006) Plant physiology, 4th edn. Sinauer Associates, Sunderland, p 764

Tamura K, Dudley J, Nei M, Kumar S (2007) MEGA4: Molecular Evolutionary Genetics Analysis (MEGA) software version 4.0. Mol Biol Evol 24:1596-1599 
Tommasini L, Svensson J, Rodriguez E, Wahid A, Malatrasi M, Kato K, Wanamaker S, Resnik J, Close T (2008) Dehydrin gene expression provides an indicator of low temperature and drought stress: transcriptome-based analysis of Barley (Hordeum vulgare L.). Funct Integr Genomic 8:387-405

Tompa P, Kovacs D (2010) Intrinsically disordered chaperones in plants and animals. Biochem Cell Biol 88:1-8

Topp GC, Davis JL (1985) Measurement of soil water content using time-domain reflectometry (TDR): a field evaluation. Soil Sci Soc Am J 49:19-24

Topp GC, Davis JL, Annan AP (1980) Electromagnetic determination of soil water content: measurements in coaxial transmission lines. Water Resour Res 16:574-582

Tschaplinski TJ, Tuskan GA, Gebre GM, Todd DE (1998) Drought resistance of two hybrid Populus clones grown in a large-scale plantation. Tree Physiol 18:653-658

Turner NC (1988) Measurements of plant water status by the pressure chamber technique. Irrig Sci 9:289-308

Vaseva II, Grigorova BS, Simova-Stoilova LP, Demirevska KN, Feller U (2010) Abscisic acid and late embryogenesis abundant protein profile changes in winter wheat under progressive drought stress. Plant Biol 12:698-707

Volaire F (2002) Drought survival, summer dormancy and dehydrin accumulation in contrasting cultivars of Dactylis glomerata. Physiol Plant 116:42-51

Volaire F (2003) Seedling survival under drought differs between an annual (Hordeum vulgare) and a perennial grass (Dactylis glomerata). New Phytol 160:501-510

Volaire F, Norton MR, Norton GM, Lelièvrè F (2005) Seasonal patterns of growth, dehydrins and water-soluble carbohydrates in genotypes of Dactylis glomerata varying in summer dormancy. Ann Bot 95:981-990

Vornam B, Gailing O, Derory J, Plomion C, Kremer A, Finkeldey R (2011) Characterisation and natural variation of a dehydrin gene in Quercus petraea (Matt.) Liebl. Plant Biol DOI: 10.1111/j.1438677.2011.00446.x

Wahid N, González-Martínez SC, El Hadrami I, Boulli A (2006) Variation of morphological traits in natural populations of maritime pine (Pinus pinaster Ait.) in Morocco. Ann For Sci 63:83-92

Welling A, Rinne P, Viherä-Aarnio A, Kontunen-Soppela S, Heino P, Palva ET (2004) Photoperiod and temperature differentially regulate the expression of two dehydrin genes during overwintering of birch (Betula pubescens Ehrh.). J Exp Bot 55 (396):507-516

Wilkins O, Waldron L, Nahal H, Provart NJ, Campbell MM (2009) Genotype and time of day shape the Populus drought response. Plant J 60:703-715

Wisniewski M, Close T, Artlip T, Arora R (1996) Seasonal patterns of dehydrins and 70-kDa heat-shock proteins in bark tissues of eight species of woody plants. Physiol Plant 96:496-505

Wisniewski M, Webb R, Balsamo R, Close TJ, Yu XM, Griffith M (1999) Purification, immunolocalization, cryoprotective, and antifreeze activity of PCA60: a dehydrin from peach (Prunus persica). Physiol Plant 105:600-608

Wisniewski ME, Bassett CL, Renaut J, Farrell R Jr, Tworkoski T, Artlip TS (2006) Differential regulation of two dehydrin genes from peach (Prunus persica) by photoperiod, low temperature and water deficit. Tree Physiol 26:575-584

Wisniewski M, Bassett C, Norelli J, Macarisin D, Artlip T, Gasic K, Korban S (2008) Expressed sequence tag analysis of the response of apple (Malus x domestica 'Royal Gala') to low temperature and water deficit. Physiol Plant 133:298-317

Yakovlev IA, Fossdal CG, Johnsen Ø, Junttila O, Skrøppa T (2006) Analysis of gene expression during bud burst initiation in Norway spruce via ESTs from subtracted cDNA libraries. Tree Genet Genom 2:39-52

Yakovlev IA, Asante DKA, Fossdal CG, Partanen J, Junttila O, Johnsen $\varnothing$ (2008) Dehydrins expression related to timing of bud burst in Norway spruce. Planta 228:459-472

Yakubov B, Barazani O, Shachack A, Rowland LJ, Shoseyov O, GolanGoldhirsh A (2005) Cloning and expression of a dehydrin-like protein from Pistacia vera L. Trees 19:224-230

Zhu B, Choi DW, Fenton R, Close TJ (2000) Expression of the barley dehydrin multigene family and the development of freezing tolerance. Mol Gen Genet 246:145-153 